\title{
Antifouling Effectiveness and Potential Toxicological Risk of an Elastomer-Based Coating against Zebra Mussels
}

\author{
Yves de Lafontaine ${ }^{1} \&$ Julie Veillette ${ }^{2}$ \\ ${ }^{1}$ Department of Fisheries and Oceans Canada, Institut Maurice-Lamontagne, Canada \\ ${ }^{2}$ Environment and Climate Change Canada, Centre Saint-Laurent, Canada \\ Correspondence: Yves de Lafontaine, Department of Fisheries and Oceans Canada, Institut Maurice-Lamontagne, \\ Canada. Tel: 1-418-775-0555. E-mail: Yves.deLafontaine@dfo-mpo.gc.ca
}

Received: October 14, 2016

Accepted: November 15, $2016 \quad$ Online Published: November 30, 2016

doi:10.5539/enrr.v6n4p125

URL: http://dx.doi.org/10.5539/enrr.v6n4p125

\begin{abstract}
The fouling of hard substrates by zebra mussels (Dreissena sp.) in freshwater ecosystems is a persistent problem which calls for antifouling treatments being fully efficient, long-lasting, and environmentally safe. The present study assessed the potential toxicological impact and the effectiveness of an elastomer-based coating containing salts that would make surfaces repulsive to zebra mussel attachment. Laboratory testing using standard analytical methods for water and wastewater, and a battery of six bioassays confirmed that the leachates from the coating exhibited no toxic response suggesting its safety to the receiving environment. In situ experiments using multi-plate collectors indicated that biofouling by zebra mussels and sponges on coated surfaces was effectively reduced by up to $97 \%$ over one growing season. Effectiveness of the coating was slightly less (82\%) during the second growing season. Results suggested that the repulsive effect would be due to the presence of salts within the elastomer-based coating affecting both zebra mussels and other freshwater organisms. Saltwater experiments indicated that the coating was totally ineffective to prevent biofouling in marine environments. In addition of being environmentally safe to use, results suggested that the coating can be an effective antifouling product for submerged structures in freshwater environments.
\end{abstract}

Keywords: antifouling, coating, freshwater, invasive species, toxicity, zebra mussels

\section{Introduction}

The introduction of zebra and quagga mussels (Dreissena polymorpha and Dreissena rostriformis bugensis) in North America has resulted in the biofouling of underwater hard substrates which led to important socio-economical and environmental consequences (Pimentel et al., 2005) as well as major impacts to freshwater biodiversity, including the decline of native benthic species in the Great Lakes (Van Appledorn \& Bach, 2007), the loss of water column primary production (Claudi \& Mackie, 1994; Brines et al., 2007) and the alteration of food web structure in lacustrine environments (Karatayev et al., 2002). Zebra mussels adhere tightly to virtually any underwater hard substrate by their tenacious proteinaceous byssal threads with adhesive plaques at the tips (Farsad \& Sone, 2012). In addition to local environmental effects caused by high densities ( $>10000$ ind. $\mathrm{m}^{-2}$ ) of zebra mussels, heavy fouling can further increase the risk of transfer and spread of these invasive species.

The biofouling by zebra mussels and other undesirable aquatic organisms can be controlled to variable degree in using various water treatment technologies based upon physical processes or toxic chemical materials (Martin, Mackie, \& Baker, 1993; Claudi \& Mackie, 1994; Morse, 2009; Bernabeu et al., 2011; Bueley et al., 2014). An alternative approach is to cover underwater surfaces with repulsive products that deter organisms fouling to levels that can be considered acceptable and of low risk of proliferation. Ideally, an antifouling coating should be non-toxic to non-target organisms, produce no toxic by-products in the environment, resist erosion over time, adhere to a variety of substrates, be easy to apply, anticorrosive, long-lasting (3-5 years), resistant to damage and cost competitive (Chambers et al., 2006; Maréchal \& Hellio, 2009). The various antifouling coatings being developed, tested and used can be divided into two treatment approaches: 1) the chemically active antifouling compounds and, 2) the surface characteristics of the substrate.

Antifouling paints that continuously release chemicals through the painted surface are the most common chemically active antifouling technologies used for zebra mussel mitigation. In spite of its versatility, this control 
method poses concerns because of potential harmful impacts on non-target organisms and their environment, and of high economic costs (Cope et al., 1997). Hence, the use of many chemicals have been banned by several countries as a result of their environmental toxicity, a classical example being the use of tributyltin (TBT) in paints applied to ship hulls and pleasure crafts (Regoli et al., 2001; Dafforn et al., 2011; Howell \& Behrends, 2010). Similarly, copper-based coatings that do not degrade rapidly were shown to produce residues that accumulate in the sediments and the biota posing a threat to aquatic environments (Dafforn et al., 2011). Environmental concerns about the toxicity of chemicals used in antifouling coatings have prompted the development of alternative chemically active antifouling technologies which would be more selective and not toxic to the environment. These include the use of naturally occurring compounds that repel aquatic organisms (Qian et al., 2010; Dafforn et al., 2011). For example, strains of Pseudomonas bacteria and their natural metabolic products were shown to selectively kill zebra mussels by intoxication (Molloy et al., 2013). The derivatives of capsaicin, a natural component of chili pepper, and other structurally similar products were shown to inhibit zebra mussel attachment (Angarano et al., 2007; Angarano et al., 2009). Marine sponges are typically unfouled by macroorganisms, and the potential antifouling capacity of natural products isolated from sponges was found to be effective against zebra mussel (Diers et al., 2004, 2006; Bowling et al., 2010). On the hand, chitin, an extract from the exosqueletton of crustaceans, was not useful to significantly reduce biofouling by zebra mussels (de Lafontaine et al., 2002). Overall, the broad effectiveness of these naturally occurring antifouling products has not yet been reported (Chambers et al., 2006; Webster \& Chisholm, 2010). Finally, other approaches have attempted to design innovative application strategies for existing biocides (Costa et al., 2008a), such as encapsulation of toxins in microscopic particles of edible material (Aldridge et al., 2006; Costa et al., 2011a), combination of toxins (Costa et al., 2011b; Costa et al., 2012), and investigation of the seasonal variation of the species' tolerance to toxins (Costa et al., 2008b).

Antifouling solutions based on the surface properties of the substrate to control aquatic fouling are usually considered to be benign to the environment because no chemical or material is released into the environment. These coatings rely on surface physico-chemical and material characteristics to deter organisms to attach or to reduce their attachment strength. These solutions include nanostructured surfaces, surface modification and foul release technologies (Chambers et al., 2006; Hellio \& Yebra, 2009). Recent advances in nanotechnology and polymer science, and the development of novel surface designs bioinspired by nature are expected to have a significant impact on the development of these new antifoulants (Callow \& Callow, 2011). Foul release technology aims to create surface characteristics that reduce the attachment strength of organisms (Chambers et al., 2006). Hence, attached organisms detach under their own weight as they grow or they are removed by water movement, as when a ship moves through the water. Among the products assessed to date, silicone was the polymer having the lowest adhesion and the best foul release capacity (Townsin \& Anderson, 2009; Lewis, 2009; Wells et al., 1997). Foul release coatings provide best results for vessels operating regularly at speeds greater than 15 knots, or they will necessitate regular cleaning (Townsin \& Anderson, 2009). Although antifouling solutions based on surface properties have proven to inhibit biofouling, they are still not widely applied to vessels due to practical shortcomings (Webster \& Chisholm, 2010; Lewis, 2009).

Another alternative technology are the non-leaching active coatings, where the chemicals are bounded to a surface and exert a repulsive effect to organisms that get in contact with the surface, but without the chemical being released into the surrounding environment (Lewis, 2009). An elastomer-based compound was recently developed to be used as an antifouling coating against zebra mussels (MD Technologies, 2008). This coating (named $\mathrm{ZebraOut}{ }^{\circ}$ ) which contains no biocide or persistent toxic compounds is an heterogeneous system made of two liquid phases. The first liquid phase is dispersed by forming small polymeric droplets and the second liquid phase is ionically charged with saline solutions to allow the attraction and solidification of the elastomer. Given that survival of zebra mussel larval stages is greatly reduced in salty environment (Kilgour et al., 1994), it was hypothesized that the presence of salts within the product would render surfaces repulsive to zebra mussel attachment. The coating can be easily applied as a spray, dries quickly and adheres to most surfaces, including metal, steel, aluminum, wood, concrete and plastic. Thickness application varies from 0.25 to $6 \mathrm{~mm}$, or more if necessary. This soft coating has an impressive extension factor of $>1000$, which makes it useful for surfaces that may suffer physical stress (MD Technologies, 2008).

The present study assessed the effectiveness and the potential environmental risk of the ZebraOut ${ }^{\odot}$ elastomer-based coating as an antifoulant against zebra mussels. The specific objectives were two-fold. First, the toxicological potential of leachates from the coating was determined in laboratory experiments to assess whether the use of the coating can pose some risk to aquatic environments. This was viewed as a pre-requisite before conducting any experiment under in situ conditions. Second, the antifouling response of the coating against zebra mussels under 
different in situ conditions over short (4-5 months) and longer period of time (11 months) was evaluated. Specifically, we quantified the percent reduction in zebra mussel fouling on coated surfaces. We also examined the effect of the coating on mussel size distribution to verify if the coating effectiveness was size-selective. The efficacy of the coating in freshwater and saltwater environments was assessed. Finally, the effects of substrate colour and the potential competitive interaction of zebra mussels with sponges were also analyzed.

\section{Method}

\subsection{Toxicological Analyses}

Toxicological testing analyses of leachates from polypropylene $15-\mathrm{cm}$ X $15-\mathrm{cm}$ plates coated with ZebraOut ${ }^{\circ}$ were performed in the laboratory. Leachates were obtained by immersing newly coated plates in glass containers filled with $3.5 \mathrm{~L}$ of deionized water for $24 \mathrm{~h}$ and the control consisted of the leachates from uncoated plates. Temperature was stable between 23.2 and $23.9{ }^{\circ} \mathrm{C}$ during the leaching period. First, contaminant analyses and water quality testing on leachates were made using standard analytical methods for water and wastewater (Greenberg et al., 1992). The results were then compared to the standard "BNQ (Bureau de Normalisation du Québec) 3660-950 - Safety of Products and Materials in Contact with Drinking Water" in order to evaluate the potential toxicity of leachates. Second, following the approach used in previous assessment studies (de Lafontaine et al., 2008; de Lafontaine et al., 2013), the potent toxicity of coating leachates on various components of the food web was evaluated by a battery of six bioassays from bacteria to fish.

The six bioassays were the Microtox (Vibrio fischeri) test, the algal (Pseudokirchneriella capricornatum) microplate assay, the Cnidaria (Hydra attenuata) test, the cladoceran (Daphnia magna) test, the microcrustacean (Thamnocephalus platyurus) test, and the trout (Oncorhynchus mykiss) hepatocyte test. The Microtox and the algal tests are two sublethal tests measuring the inhibitory effect of toxic compounds on cell physiology and growth. The four others are lethal tests measuring the proportion of dead organisms resulting from toxic exposure over different time periods. Although their experimental protocols vary slightly, all assays are based on a common procedure that consists of exposing, under controlled laboratory conditions, living organisms to a dilution series of water samples and to note and quantify the observed effects. The Microtox test was conducted using a bacterial concentration of $1 \times 10^{6}$ cells ml-1 in four replicates for each of the 10 diluted concentrations with an exposure time of $15 \mathrm{~min}$. The algal test consisted of 10 diluted concentrations with five replicates, each one with 10000 cells ml ${ }^{-1}$ for a $72 \mathrm{~h}$ exposure time at $24^{\circ} \mathrm{C}$. The Cnidaria test was conducted for $96 \mathrm{~h}$ using seven diluted concentrations with three replicates and three organisms per replicate. The cladoceran test used five newly hatched $(<24 \mathrm{~h}$ old $)$ individuals in three replicates for the six dilutions tested and the contact time was 48 $\mathrm{h}$ at $20{ }^{\circ} \mathrm{C}$. For the microcrustacean test, three replicates of 10 larvae were used for each of the six diluted samples at dark at $25{ }^{\circ} \mathrm{C}$ for $24 \mathrm{~h}$. Data were analysed to compute various endpoint values $\left(\mathrm{LC}_{50 / 25}: 50 / 25 \%\right.$ lethal concentration; $\mathrm{EC}_{50}: 50 \%$ effect concentration; $\mathrm{IC}_{50}: 50 \%$ inhibitory concentration; NOEC: no observed effect concentration) depending on the assay. The results are expressed in toxic units (TU), which correspond to the inverse of the dilution factor required to reduce potent toxicity at the selected endpoint concentration. All the toxicity tests were conducted according to standard procedures and protocols currently used by Environment Canada (see references in de Lafontaine et al. (2008) and in Gagné (2006) for the rainbow trout hepatocyte test). All bioassays using experimental animals during this study were conducted following approved protocols in accordance to guidelines provided by the GLLFAS/NWRI animal care committee of Environment Canada.

\subsection{Coating Effectiveness}

\subsubsection{Experimental Design}

Antifouling effectiveness was determined in 4 in situ experiments conducted in 4 different years using multi-plate collectors as previously described and used for zebra mussel colonization experiments by de Lafontaine et al. (2002). Each experiment consisted in a series of multi-plate collectors submerged for a period of 4-5 months during the summer and autumn months (June-October), at sites in the St. Lawrence River (Canada) where zebra mussels are established (Table 1). During experiment \#2, five collectors at Bassin Louise (Quebec City) remained submerged for an 11-month period to assess the long-term adherence of mussels to coatings. Multi-plate collectors were made of three white polystyrene (Experiments \#1, 2 and 3) or grey polyvinyl chloride ( $\mathrm{PVC}$, Experiment \#4) $15 \mathrm{~cm} \times 15 \mathrm{~cm}$ plates attached at $3 \mathrm{~cm}$ intervals to a central stainless steel rod with an eyebolt (Figure 1). Since different plastic types were used in different years, it was assumed that it did not introduce a confounding factor to the study design. The collectors were deployed horizontally with the upper plate being identified as Plate A, the middle, as Plate B and the lower plate, as Plate C. In experiments $\# 1,2$ and 3 , each collector was attached to a polypropylene rope to a sub-surface float, which was suspended at a depth of $4 \mathrm{~m}$ and attached to a floating dock at the surface. The collector was maintained straight in the water 
column by a cement brick that was attached to the bottom of the collector. For experiment \#4, eight collectors were attached in pairs of coated and uncoated units inside a rigid steel frame (1 $\mathrm{m} \mathrm{X} 2 \mathrm{~m}$ ) with four $45 \mathrm{~cm}$-long legs welded perpendicular at each corner of the frame. The frame was then suspended along the side of a dock or pier with the legs keeping the frame away from the dock wall. This design was adopted to eliminate the risk of loosing individual collectors.

Experiment \#1 conducted at Bassin Louise (Quebec City) was a preliminary trial for comparing the antifouling effectiveness of $\mathrm{ZebraOut}^{\odot}$ against other surfaces having different degree of roughness. Plates coated with ZebraOut $^{\circ}$ were black-coloured and characterized by a surface texture similar to an orange skin. Sand and chitin coated plates consisted of sand or chitin particles sprayed on an epoxy polymer yielding a beige-coloured rough surface. Plates coated with epoxy only and uncoated plates were all slick and served as control plates. In all other experiments, coated plates were black-coloured while control (uncoated) plates were either white or black to test the influence of substrate colour on colonization. Experiment \#2 was conducted at four different sites having different mussel densities. Experiment \#3 conducted at Bassin Louise was designed to assess long-term durability of the coating, by re-utilizing plates that had been used in the previous year (Experiment \#2), cleaned and kept frozen at $-20^{\circ} \mathrm{C}$ during the winter months prior to be deployed again for another season. This was done to mimic the potential effect of wintertime freezing conditions exposure on the effectiveness of the coated plates. Finally, experiment \#4 was designed to test the effectiveness of the coating against saltwater organisms at piers and docks of three sites in the Estuary and the Gulf of St. Lawrence : at the St-Joseph-de-la-Rive marina in the middle St.Lawrence estuary $\left(47.449^{\circ} \mathrm{N} ; 70.365^{\circ} \mathrm{W}\right)$, at the Maurice-Lamontagne Institute dock in Mont-Joli along the lower St.Lawrence estuary $\left(48.643^{\circ} \mathrm{N} ; 68.166^{\circ} \mathrm{W}\right)$, and at the Carleton marina in Baie-des-Chaleurs $\left(48.101^{\circ} \mathrm{N} ; 66.129^{\circ} \mathrm{W}\right)$ in the Gulf of St.Lawrence. Collectors were also deployed at Bassin Louise (Quebec City) and served as a freshwater control. Overall, the Bassin Louise site was selected in all experiments which allowed comparison between years at that site.

Usually 8 collectors per site were used in the different experiments. The number of collectors retrieved at a given site and year varied between 5 and 8, due to some lost or vandalism. Upon their retrieval, collectors were brought back to the laboratory and stored in $-20^{\circ} \mathrm{C}$ freezers. Prior to laboratory analysis, digital photographs were taken of each multi-plate collector from 6 different angles ( 4 sides, 1 top, 1 bottom). Once dismantled, digital photographs of each plate side were also taken. These photographs were used to qualitatively describe the spatial distribution of mussels on plates and to estimate surface area by sponges on each plate side.

Table 1. Summary of experimental design for each in situ experiment.

\begin{tabular}{llllll}
\hline Experiment & Substrate coating & Substrate colour & Number of collectors & Exposure time (days) \\
\hline \multirow{4}{*}{$\# 1$} & & no coating & white & 1 & 102 \\
& & Sand & light beige & 2 & 94 \\
& Bassin Louise (Quebec City) & Epoxy & light beige & 1 & 94 \\
& & $15 \%$ chitin & light beige & 2 & 102 \\
& & ZebraOut & black & 1 & 102 \\
\hline \multirow{4}{*}{$\# 2$} & ZebraOut & black & 2 & 120 \\
& Bassin Louise & no coating & white/black & $2 / 2$ & 120 \\
& BLO2000 & ZebraOut & black & 2 & 337 \\
& & no coating & white/black & $1 / 2$ & 337 \\
& Montreal marina & ZebraOut & black & 2 & 120 \\
& MON2000 & no coating & white/black & $1 / 1$ & 120 \\
& Longueuil marina & ZebraOut & black & 2 & 120 \\
& LON2000 & no coating & white/black & $1 / 1$ & 120 \\
& Ile Perrot marina & ZebraOut & black & 2 & 120 \\
& IPE2000 & no coating & white/black & $1 / 1$ & 120 \\
\hline \multirow{2}{*}{$\# 3$} & Bassin Louise & ZebraOut & black & 2 & 148 \\
& BLO2001 & no coating & white/black & $1 / 1$ & 148 \\
\hline \multirow{2}{*}{ Bassin Louise } & ZebraOut & black & 4 & 145 \\
& BLO2003 & no coating & black & 4 & 145 \\
\hline
\end{tabular}




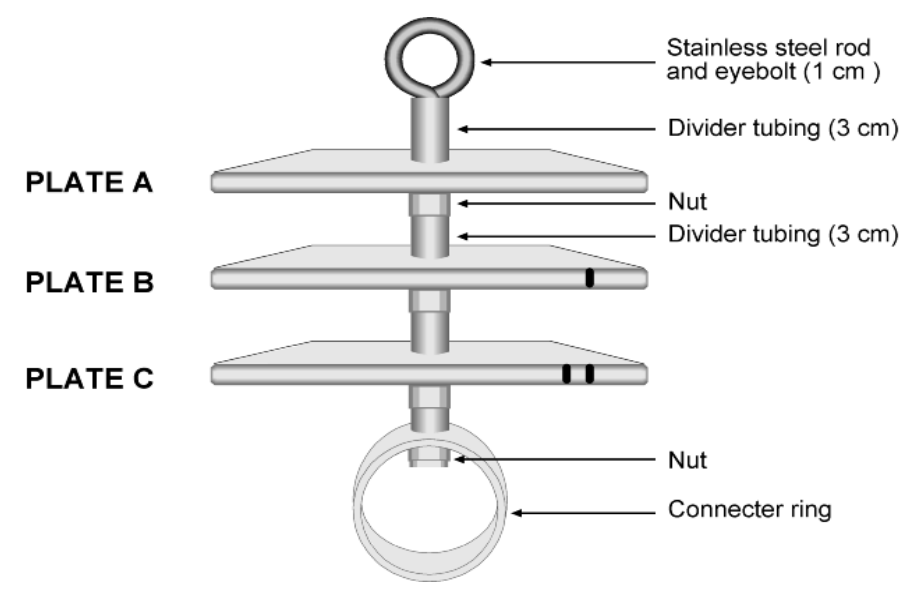

Figure 1. Schematic view of a multi-plate collector

\subsubsection{Laboratory Analyses}

Zebra mussel abundance was obtained by counting the number of zebra mussels that were scraped off from each plate side of every collector. Due to the small size of some individuals, counting was performed under a stereoscopic microscope. From each plate side, 50 or 100 mussels were randomly selected for shell measurement using a micrometer in the stereomicroscope eyepiece. Shell length was measured $( \pm 0.01 \mathrm{~mm})$ as the distance from the umbo to the opposite shell edge along the animal's frontal plane. For experiment \#2 (plates immersed during 11 months at Bassin Louise only), \#3 and \#4, the percentage of the total surface area of each plate side covered by sponges was determined digitally by means of an image-analyzing system using MapInfo (version 4.5) software. In experiment \#4, the dry biomass of the fouling material from each plate side of every collector was also determined by scraping it off with the help of stereomicroscopic magnifying glass or binoculars, and the resulting material was categorized by organisms. When organisms were embedded into algal material, they were categorized as 'algae'. Zebra mussels were enumerated prior to weighing. In all experiments, all mussels were assumed to be alive at the time of collectors retrieval. All samples were returned to the freezer after analysis.

\subsubsection{Data Analyses}

Differences in mussel abundance, dry weight and sponge percent coverage were fitted to generalized linear mixed models (GLIMMs) with overdispersed Poisson, lognormal and beta distributions, respectively. Treatment effects were tested against whole collector variability to avoid the possibility of pseudo-replication among collector plates. Plates and sides were ranked within collectors to assess their homogeneity with Fisher's exact tests. Variability in settlement densities was compared between plate sides with Conover tests. Collector-sampled mussel length distributions were compared with Wilcoxon (location), Conover (dispersion) and Kolmogorov-Smirnov (shape) tests. The results on mussel abundance variability between plate sides within a collector (see the Results section) confirmed those previously reported by de Lafontaine et al. (2002) who suggested using counts from plate undersides in order to minimize variability. Therefore, statistical analyses in this study were performed on zebra mussel abundance, dry biomass or sponge percent coverage per plate undersides only.

Antifouling coating efficiency was expressed as the difference between the quantity of biological material (expressed as abundance, dry biomass or percent coverage) attached on the coated and the uncoated plates in each experiment and was calculated as:

$$
\text { Efficiency }(\%)=100 * \text { (uncoated-coated }) \text { /uncoated }
$$

Relationships between sponge percent coverage and mussel abundance were assessed using Spearman correlations. All tests were done using SAS/STAT ${ }^{\circledR} 12.1$ for Windows, at a 0.05 probability significance level.

\section{Results}

\subsection{Toxicological Response}

Results from all water quality and contaminant analyses realized on coating leachates were consistently well below the guideline criteria of the Bureau de Normalisation du Québec (BNQ) for products and materials in 
contact with drinking water (Table 2). Results from the six ecotoxicological bioassays revealed no potential toxicity of leachates from the coating (Table 3), as indicated by the toxic response of the different endpoints being all equal or below 2 toxic units. The significant increase in specific conductivity in leachates from the coated plates ( 0.5 to $\left.93.1 \mu \mathrm{S} \mathrm{cm}^{-1}\right)$ was probably caused by the salting out from the coating. If trace metals would become bioavailable by this process, they do not however induce any toxic response as suggested by the ecotoxicological bioassays results. Percentage of dissolved oxygen measured at the beginning and at the end of the $24 \mathrm{~h}$ leaching period indicated no difference between control and coated plates leachates. Leaching of coating surface may be considered as completed after 24 hours. An additional Microtox bioassay with leachates from coated plates during 72 hours revealed no additional toxicity. All the above laboratory tests revealing no toxic response suggested the innocuity of the coating for the receiving environment.

Table 2. Results of water quality analyses of the coating leachates in comparison to the BNQ (Bureau de Normalisation du Québec) criteria for the Safety of Products and Materials in Contact with Drinking Water (protocol 3660-950). Blanks were substracted from the results

\begin{tabular}{llll}
\hline Water quality parameters & Analytical methods & BNQ guidelines $\left(\mathrm{mg} \mathrm{L}^{-1}\right)$ & Results $\left(\mathrm{mg} \mathrm{L}^{-1}\right)$ \\
\hline Arsenic & $3114-\mathrm{B}$ & 0.05 & $<0.001$ \\
Baryum & $3120-\mathrm{B}$ & 1 & $<0.01$ \\
Cadmium & $3120-\mathrm{B}$ & 5 & $<0.02$ \\
Chromium & $3500-\mathrm{C}, \mathrm{D}$ & 0.05 & $<0.001$ \\
Lead & $3120-\mathrm{B}$ & 0.05 & $<0.001$ \\
Mercury & $3112-\mathrm{B}$ & 0.001 & $<0.0002$ \\
Selenium & $3114-\mathrm{B}$ & 0.01 & $<0.001$ \\
Silver & $3120-\mathrm{B}$ & 0.05 & $<0.0003$ \\
Tin & $3120-\mathrm{B}$ & 0.05 & $<0.01$ \\
Cyanides & $4500-\mathrm{CN}, \mathrm{E}$ & 0.2 & 0.09 \\
Fluoride & $4500-\mathrm{F}, \mathrm{C}$ & 1.5 & 0 \\
Phenolic compounds & $5530-\mathrm{B}, \mathrm{C}$ & 0.002 & $<0.002$ \\
Vinyl chloride & EPA-524 & 0.05 & $<0.001$ \\
Nitrites-nitrates & $4500-\mathrm{NO}, \mathrm{H}$ & 10 & $<0.05$ \\
Odor & $2150-\mathrm{B}$ & $<16$ & 1 \\
Taste & $2160-\mathrm{C}$ & $<4 / 5$ & 1 \\
Color & $2120-\mathrm{B}$ & $<16$ & $<1$ \\
\hline
\end{tabular}

\subsection{Colonization on Multi-Plate Collectors}

All uncoated plates were colonized by zebra mussels with densities on underside plates ranging from 133 to 33 778 individuals per $\mathrm{m}^{2}$ (mean of 14452 individuals per $\mathrm{m}^{2}$ ). Densities on control plates at the Bassin Louise site were always higher than at other locations, and were 3 to 4 times higher in 2001 and 2003 than in 1999 and 2000 at that site. Both dreissenid mussels species were found but Zebra mussel largely dominated while Quagga mussel accounted for less than $2 \%$ of all mussels on uncoated plates in the four experiments at Bassin Louise. Zebra mussels accounted for most (>99\%) of the fouling biomass on the plates, the remainder consisting of algae and sponges. Sponges coverage varied between 0 to $50 \%$ of the surface of uncoated plates (mean $=15 \pm$ 17\%) and was more important in 2000 and 2001 than in 2003.

Among the six plate sides within every collector, the topside of plate A was significantly the least colonized surface by zebra mussels (Fisher's exact test, $\mathrm{P}<0.0001$ ). The topsides of plates $\mathrm{B}$ and $\mathrm{C}$ were significantly more colonized than their undersides for uncoated plates (GLIMMs, $\mathrm{P}=0.05$ ) but not for the coated plates (GLIMMs, $\mathrm{P}=0.56$ ). A monolayer of zebra mussels was always observed on the coated plates while very few mussels were occasionally attached to conspecifics on the uncoated plates. As previously described in de Lafontaine et al. (2002), zebra mussels tend to aggregate more at the center than near the edges of the coated plates. Probably as a result of higher densities, mussels were distributed more homogeneously on the uncoated plates. Mussel abundance on plate undersides within every collector showed less variability (CVs of coated plates: $49 \%$, CVs of uncoated plates: $20 \%$ ) than that of plate topsides (excluding plate A; CVs of coated plates: $72 \%$; CVs of uncoated plates: $29 \%$ ). These differences in variability were significant for uncoated plates (Conover test, $\mathrm{P}=0.01$ ) but not for the coated plates (Conover test, $\mathrm{P}=0.17$ ). These results justified the selection of the underside of plates for statistical analyses. Difference between white- and black-coloured plates 
was not statistically significant for zebra mussel abundance $(\mathrm{P}=0.10)$ and sponge colonization $(\mathrm{P}=0.16)$ on uncoated plates. Therefore, it was decided to pool results from both coloured plates for statistical analyses.

Table 3. Results of the six ecotoxicological bioassays (expressed in toxic unit - TU) from coating leachates analyses and water specific conductivity measured at the beginning $(0 \mathrm{~h})$ and the end $(24 \mathrm{~h})$ of the leaching period. Results for uncoated and coated plates are means of triplicates. Various endpoints for bioassays are: $\mathrm{LC}_{50 / 25}=50 / 25 \%$ lethal concentration; $\mathrm{EC}_{50}=50 \%$ effect concentration ; $\mathrm{IC}_{50}=50 \%$ inhibitory concentration; $\mathrm{NOEC}=$ no observed effect concentration

\begin{tabular}{lllll}
\hline Bioassay & Endpoint & Control & Uncoated plates & Coated plates \\
\hline Microtox & $\mathrm{IC}_{50}$ & $<2.0$ & $<2.0$ & $<2.0$ \\
& $\mathrm{NOEC}$ & 2.0 & 2.0 & 2.0 \\
Algae & $\mathrm{IC}_{50}$ & $<1.0$ & $<1.0$ & $<1.0-1.1$ \\
& $\mathrm{NOEC}$ & 1.0 & 1.0 & 1.4 \\
Cnidaria Hydra & $\mathrm{LC}_{50}$ & $<1.0$ & $<1.0$ & $<1.0$ \\
& $\mathrm{EC}_{50}$ & $<1.0$ & $<1.0$ & $<1.0$ \\
Daphnia & $\mathrm{EC}_{50}-24 \mathrm{~h}$ & 1.2 & $<1.0-1.1$ & $<1.0$ \\
& $\mathrm{EC}_{50}-48 \mathrm{~h}$ & 1.3 & $>1.0-1.1$ & $<1.0$ \\
Microcrustacean & $\mathrm{LC}_{50}$ & $<1.0$ & $<1.0$ & $<1.0$ \\
& $\mathrm{LC}_{25}$ & $<1.0$ & $<1.0$ & $<1.0$ \\
Trout hepatocyte & $\mathrm{LC}_{50}-48 \mathrm{~h}$ & $<2.0$ & $<2.0$ & $<2.0$ \\
& & & & 0.5 \\
Specific conductivity & $0 \mathrm{~h}$ & 0.4 & 0.5 & 93.1 \\
$\left(\mu \mathrm{S} \mathrm{cm}\right.$ c $\left.^{-1}\right)$ & $24 \mathrm{~h}$ & 1.0 & 1.4 & \\
\hline
\end{tabular}

\subsection{Effectiveness of Coating in Freshwater}

\subsubsection{Differences in Colonization}

Results from the preliminary trial study (Experiment \#1) showed that ZebraOut ${ }^{\odot}$ was the only really effective coating to significantly reduce zebra mussel abundance on plates (Figure 2; $\mathrm{P}=0.0004$ ). The antifouling efficiency of $\mathrm{ZebraOut}^{\circ}$ was $92 \%$ while that of other coatings was less than $20 \%$ relative to the uncoated plates. The sand coated plates yielded the highest density of zebra mussels, being $8 \%$ higher than that on the smoother control plates. The efficiency of the ZebraOut ${ }^{\odot}$ coating was confirmed in subsequent experiments and ranged between 82 and 97\% (Figure 3a). The abundance of zebra mussels was always significantly greater on uncoated plates than on coated plates in every experiment after 5 months of immersion (BLO2000: $\mathrm{P}<0.0001$; MON2000: $\mathrm{P}=0.0123$; LON2000: $\mathrm{P}=0.0454$; BLO2001: $\mathrm{P}=0.0004$; $\mathrm{BLO} 2003: \mathrm{P}<0.0001)$. In experiment $\# 2$, the coating efficiency was 95 and 97\% at the Longueuil (LON2000) and Bassin Louise (BLO2000) sites respectively, both characterized by relatively high zebra mussel abundance. The efficiency was $82 \%$ at Montreal marina (MON2000) but the very low abundance of zebra mussels $(<15$ individuals per control plate) at that site yielded less precise quantitative estimation of coating efficiency. The absence of any zebra mussel colonization at the Ile Perrot site did not allow the calculation of efficiency at that site. ZebraOut ${ }^{\mathcal{O}}$ was still effective in reducing zebra mussels abundance on plates submerged during 11 months $(\mathrm{P}=0.0001$; Figure $3 \mathrm{~b})$, but efficiency declined slightly from $97 \%$ to $87 \%$, between 5 and 11 months of immersion. The lowest antifouling efficiency $(82.5 \%)$ was noted in experiment \#3 (BLO2001) when testing plates used in the previous year. Results from experiment \#4 at Bassin Louise (BLO2003) indicated a mean efficiency of $86 \%$ in reducing zebra mussel abundance on coated plates after 5 months. In terms of biomass, the reduction efficiency was only $69.2 \%$, with the dry biomass of zebra mussels on the coated plates (mean \pm s.e. $=4.16 \pm 0.86 \mathrm{mg}$ ) being significantly lower than that on the uncoated plates (mean \pm s.e. $=13.52 \pm 1.46 \mathrm{mg})(\mathrm{P}=0.0035)$. The coating did also significantly reduce sponge fouling by 52 to $64 \%$ during three experiments $(\mathrm{P}=0.0015$; Figure $3 \mathrm{c})$. There was no significant correlation between sponge coverage and mussel abundance within each experiment $(\mathrm{P}=0.18)$. 


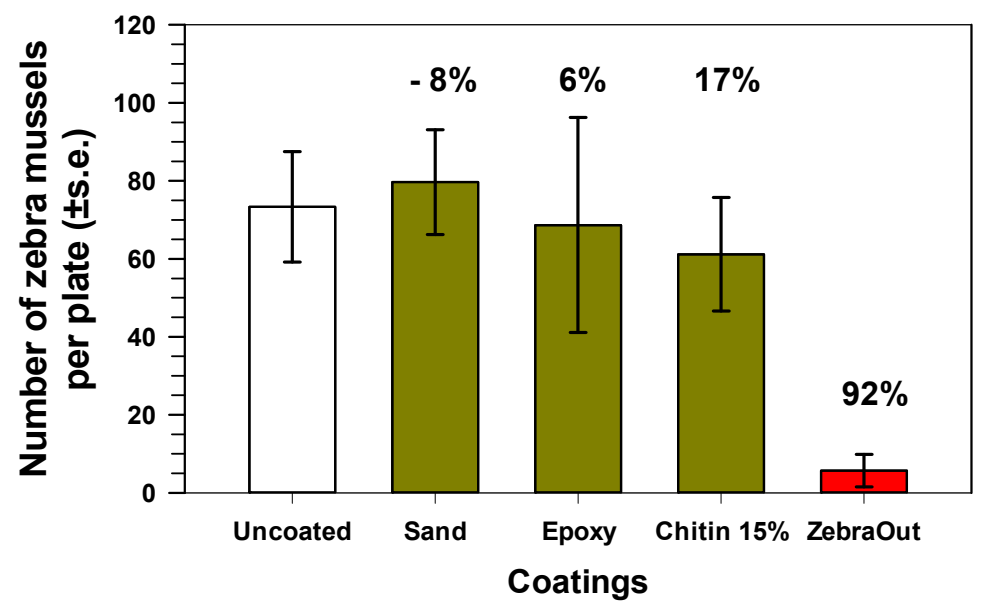

Figure 2. Abundance of zebra mussels (mean number \pm s.e.) per plate underside treated with different coatings in experiment \#1. Effectiveness expressed in percent change relative to uncoated polystyrene plate (control) is indicated for each coating
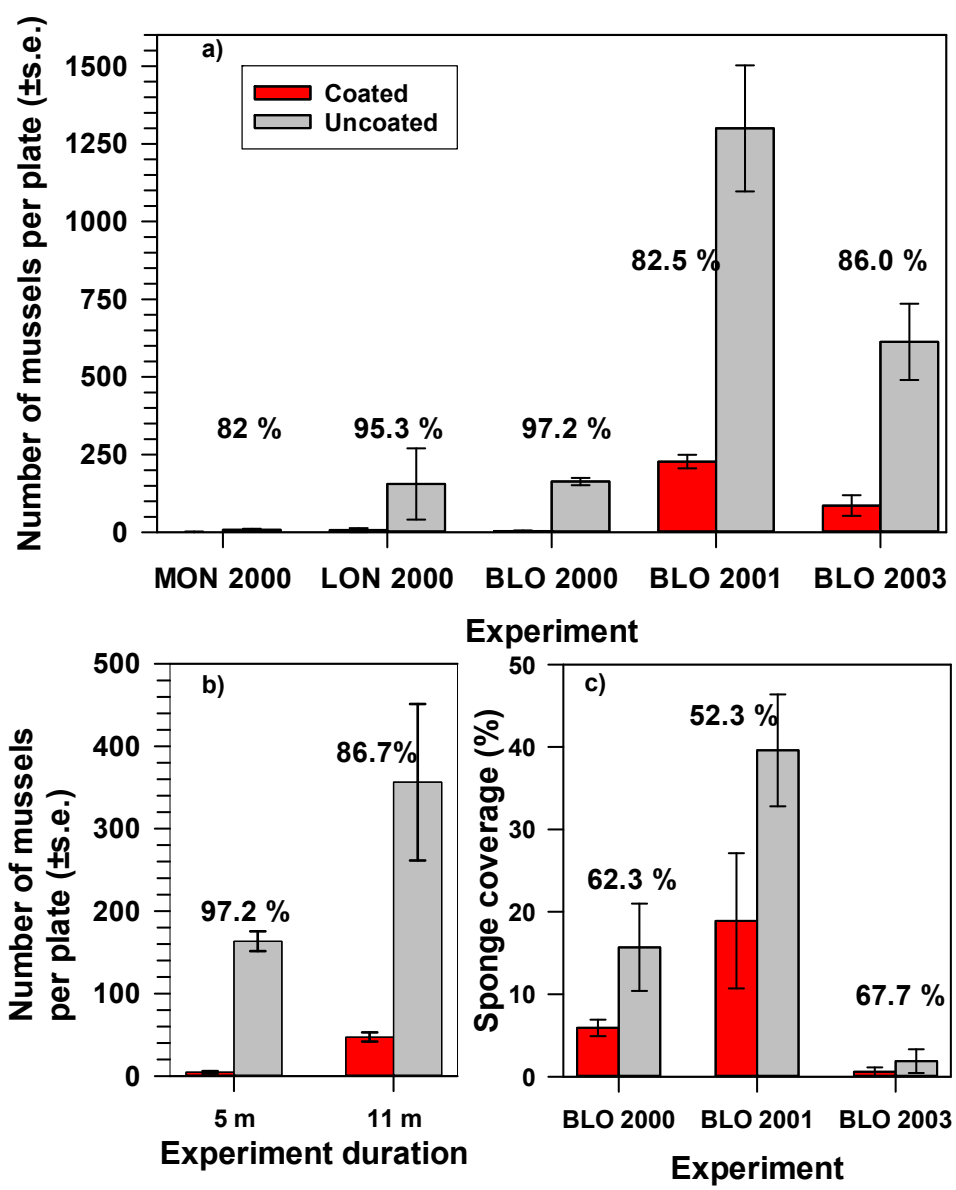

Figure 3. Differences in a) zebra mussel abundance (mean \pm s.e.) on coated and uncoated plates in different experimental locations; $b$ ) zebra mussel abundance (mean \pm s.e.) on coated and uncoated plates after 5-months and 11-months immersion time at Bassin Louise in experiment \#2 (BLO2000); c) sponge coverage area (\%, mean \pm s.e.) for coated and uncoated plates in three experiments. Effectiveness expressed in percent change is indicated above every experiment 


\subsubsection{Zebra Mussel Size Distribution}

The size distribution of zebra mussels was unimodal on the plates immersed for 11 months in experiment \#2 (BLO2000) and bimodal on those submerged for 5 months in experiment \#4 (BLO2003) (Figure 4). In experiment \#2, the average size of mussels did not significantly $(\mathrm{P}=0.54)$ differ between coated (mean= $5.64 \pm$ $2.11 \mathrm{~mm}$ ) and uncoated plates (mean= $5.99 \pm 2.80 \mathrm{~mm}$ ). The size range of mussels on coated plates was smaller $(\mathrm{P}=0.03)$ and less variable $(\mathrm{P}<0.0001)$ than that on uncoated plates. For experiment $\# 4$, statistical analysis performed on the two size classes (i.e. $<$ and $>2.8 \mathrm{~mm}$ of shell length) separately revealed that individuals of both size classes were significantly larger on coated plates than on uncoated plates (size class 1: mean on coated plates $=2.20 \pm 0.16 \mathrm{~mm}$, mean on uncoated plates $=1.50 \pm 0.12 \mathrm{~mm}, \mathrm{P}=0.01$; size class 2 : mean on coated plates $=10.00 \pm 0.11 \mathrm{~mm}$, mean on uncoated plates $=7.70 \pm 0.11, \mathrm{P}<0.0001)$. Their size distribution was also different between the coated and uncoated plates (size class 1: $\mathrm{P}=0.008$; size class 2 : $\mathrm{P}<0.0001$ ). The presence of larger mussels on the coated plates in BLO2003 contributed to the lower coating efficiency for biomass $(69.2 \%)$ than for abundance $(86 \%)$ estimates in this experiment.

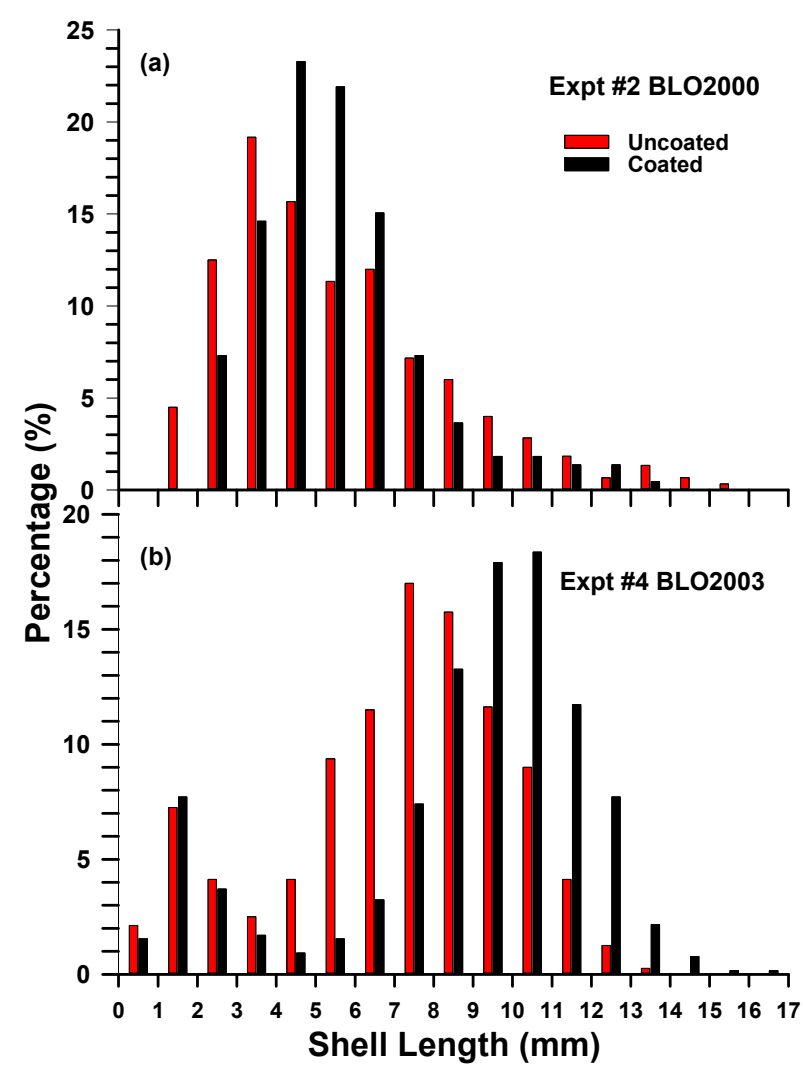

Figure 4. Zebra mussel size distribution on coated and uncoated plates immersed during a) 11 months (BLO2000) and b) 5 months (BLO2003)

\subsection{Effectiveness of Coating in Seawater}

Results from experiment \#4 conducted at the three saltwater locations indicated clearly that the ZebraOut ${ }^{\odot}$ coating was not repulsive to marine organisms. Overall, the dry biomass of organisms colonizing the coated plates was only $11 \%$ or less smaller than that measured on the uncoated plates (St-Joseph-de-la-Rive: $8.9 \mathrm{mg} \mathrm{m}^{-2}$ on coated plates and $10.2 \mathrm{mg} \mathrm{m}^{-2}$ on uncoated plates; Mont-Joli: $182.2 \mathrm{mg} \mathrm{m}^{-2}$ on coated plates and $198.7 \mathrm{mg} \mathrm{m}^{-2}$ on uncoated plates; Carleton: $140.4 \mathrm{mg} \mathrm{m}^{-2}$ on coated plates and $142.2 \mathrm{mg} \mathrm{m}^{-2}$ on uncoated plates). Differences were not statistically significant at any location $(\mathrm{P}>0.10)$. The community composition varied between the experimental sites but was largely dominated by macroalgae at all sites, while blue mussels, sponges, sea stars, gastropods, barnacles and Caprellidae were also present on some plates. Mud was also present on some plates of all collectors immersed at Mont-Joli and Carleton. 


\section{Discussion}

\subsection{Coating Effectiveness}

Results of in situ experiments demonstrated that the elastomer-based coating had a significant repulsive effect against zebra mussels. In terms of abundance, fouling by mussels on coated surface was reduced by 82 to $97 \%$ relative to control uncoated plates (Figures $2 \& 3$ ). Results on sponge coverage revealed also that the effectiveness of the coating was not restricted to zebra mussel colonization only but would apply against other freshwater organisms. The lack of toxic response in all toxicological assays done with coating leachates (Tables $2 \& 3$ ) further suggested that this repulsive effect would not be due to biocides or toxic products at the surface of the coating. The repulsive effect would presumably be due to the presence of salts within the elastomer-based coating as part of the solidification process. This was confirmed by the saltwater experiments showing that the coating was not effective against saltwater organisms and that the presence of salts within the coating was not toxic and did not stop attachment and colonization of organisms in saltwater environments. Therefore, it appeared that the effectiveness of the elastomer-based coating would be thus limited to freshwater environments and that the coating would be totally useless as an antifouling agent in marine waters.

Zebra mussels attachment depends on the substratum properties (Ackerman et al., 1996) and is modulated by various environmental factors including salinity, water turbulence and presence of biofilm (Kavouras \& Maki, 2003a,b) as well as the presence of conspecifics (Kobak, 2001, 2006). Grutters et al. (2012) found that zebra and quagga mussels did not produce byssal threads in standing waters at salinities of 4 PSU and higher, implying that attachment to substrates cannot occur under these conditions. Laboratory experiments showed that the incipient lethal salinity of post-veligers and adult stages of zebra mussels is 4.5 and 2 PSU respectively (Kilgour et al., 1994), suggesting that the younger developmental stages would be slightly more tolerant to ambient salinities. Post-veliger stages were the most sensitive life stage to water salinity and may therefore limit distribution in saltwater environments. The saline condition at the immediate surface of the elastomer-based coating used in our experiment is unknown but would presumably be high enough to limit attachment of zebra mussels post-veligers and other freshwater organisms. Results from our experiment did not permit to determine if the observed repulsive effect was due to the non-attachment of post-veligers at the time of settlement or to the settlement of organisms followed by the movement and detachment of the new settlers. Presumably, the elastomer-based coating may be especially repulsive for zebra mussel larvae that detach from coated plates after the initial settlement. This first contact of mussel larvae with the substrate would be largely stochastic whereas secondary migration would reflect a choice of the juvenile or adult mussel for a preferred substrate (Folino-Rorem et al., 2006). Studies showed that zebra mussels can settle on a substratum and then search for a suitable site to attach by crawling at the surface of the substrate (Kobak \& Kakareko, 2009). The proximate factors stimulating the non-attachment or detachment of zebra mussels to a substrate are unknown. It is thought that unsuitable conditions may induce mussels detachment since post-settlement migrations of byssate mussels do occur in nature (Ackerman et al., 1994). The attachment strength of mussels would be weaker in bad conditions (Kobak, 2006), which facilitates post-settlement migrations. Also, the attachment strength of blue mussels (Mytilus edulis) (Carrington, 2002) and zebra mussels (Kobak, 2006) was found to increase with mussel size, implying that smaller mussels may have had more difficulty remaining on coated plates versus uncoated plates.

The use of black- or white-coloured plates had no significant influence on zebra mussel abundance and sponge colonization. Previous studies using settlement plates pointed to the preference of different groups of biofoulers for dark areas (Swain et al., 2006; Kobak et al., 2009). However, the long term effect of surface colour may be reduced as biofilms develop (Swain et al., 2006). In a previous study examining the performance of a chitin-based coating (de Lafontaine et al., 2002), it was hypothesized that higher degree of substrate roughness may enhance the fixation and settlement of zebra mussels on collectors plate. The results of the present study did not confirm this hypothesis, as the abundance of zebra mussels on rough substrates (sand and $15 \%$ chitin coatings) was not significantly different than that on smooth substrates (uncoated and epoxy coatings) (Figure 2). Notwithstanding its rougher texture compared to the uncoated plates, the elastomer-based coating was highly effective to reduce zebra mussel fouling. This may also imply that coating effectiveness measured in our experiments are low estimates, as the colonization of uncoated plates with a texture similar to the elastomer-based coating could have been even greater. The lack of significant correlation between sponge coverage and mussel abundance suggested that space competition of mussels with sponges was not a confounding factor in our study. Other studies demonstrated that sponges and zebra mussels are space competitors for hard substrates, and sponges can outcompete zebra mussels as they overgrow and kill zebra mussels by interfering with their feeding and respiration activities (Molloy et al., 1997; Early \& Glonek, 1999; Lauer \& Spacie, 2004; Lancioni \& Gaino, 2005). Our results indicating very low densities of mussels on coated 
plates suggested that substrate space may not be saturated, thus limiting sponge and mussel competitive interactions. It is possible that competition would have occurred given a longer exposure period or longer duration of experiment.

\subsection{Colonization on Multi-Plate Collectors}

Densities of zebra mussels on uncoated plates immersed during one growing season (4-5 months) were within the range of that reported in other colonization studies using plate collectors (de Lafontaine et al., 2002; Kobak, 2005), or an order of magnitude lower (Marsden \& Lansky, 2000). The colonization rate and the abundance of zebra mussels on uncoated plates varied between sites and years and were extremely low at the Montreal marina site (MON2000) and absent at Ile Perrot site (IPE2000) where presumably local factors may be limiting for zebra mussel colonization. Interannual differences in zebra mussels abundance at Bassin Louise may reflect variations in zebra mussel larval production from year to year at that site. Earlier dates of collectors deployment and the longer experimental duration in the last two experiments (\#3 and \#4) may have also contributed to catch more spawning events and therefore increase the colonization probability yielding higher mussel densities in these experiments. Zebra mussels generally produce several spawning events per year in areas where water temperature $>12^{\circ} \mathrm{C}$ (Ram et al., 1996). In the St. Lawrence River, the larval production season may extend from May to October and larval peak densities generally occur in June and July (de Lafontaine et al., 1995; Cusson \& de Lafontaine, 1997).

Zebra mussel spatial distribution within collectors can be explained by mussels preference for shaded habitats (Marsden \& Lansky, 2000; de Lafontaine et al., 2002; Kobak \& Nowacki, 2007). Collectors were suspended within the euphotic zone at Bassin Louise where measured light level at $4 \mathrm{~m}$ depth corresponded to 9.4 to $13.7 \%$ of surface light (de Lafontaine et al., 2002). The much lower abundance of mussels on topside of plate A (the most light exposed surface of the collector) is likely the consequence of a high incoming light level. This plate provided shade to the topsides of plates $\mathrm{B}$ and $\mathrm{C}$ which were more colonized than plate A. As previously observed by de Lafontaine et al. (2002), the aggregation of zebra mussels at the center of the plates (excepted for the topside of plate A) may result from the movement of juvenile mussels toward the center of the plates after their settlement to reduce light exposure near the edges of the plates. However, when space for hard substrata become saturated in the most shaded areas (as it may happen on uncoated collectors), zebra mussels would then spread to the remaining space available (Marsden \& Lansky, 2000), leading to a more homogeneous distribution as observed on uncoated plates in our experiments.

\subsection{Zebra Mussel Size Distribution}

Analysis of the size distribution of mussels between coated and uncoated plates in the different experiments did not permit to reach firm conclusion on a size-selective effect of the coating for zebra mussels. While the mean size of mussels did differ significantly between coated and control plates in experiment \#2, the larger size of mussels on coated plates relative to uncoated plates for both size classes in experiment \#4 (Figure 4) may likely be due to post-settlement movement. This variability between experiments could be due in part to the difference in collectors deployment. Individual collectors were separately suspended using a rope in experiment \#2 while collectors were attached to a rigid frame in experiment \#4, a set-up that may favor mussels translocation between the fouled frame and the collectors.

\subsection{Coating Durability}

When used for the first time, the antifouling efficiency of the elastomer-based coating against zebra mussels was very high ranging from $82 \%$ to $97 \%$ over one growing season (4-5 months). The efficiency was slightly reduced after 11 months (87\%) compared to 5 months immersion $(97 \%)$. When re-using plates for a second growing season (BLO2001), the efficiency was $82.5 \%$, a reduction of $15 \%$ relative to that of the first year $(97 \%)$. These results suggest that while the elastomer-based coating can effectively slow down zebra mussel colonization, its repulsive effect would decrease over time. Presumably, salts can be gradually leached from the coating rendering coated surfaces less repulsive to mussels post-veligers. Given that the most critical requirement for an antifouling coating is to maintain an adequate fouling protection for extended exposure periods (Sanchez \& Yebra, 2009), future in situ testing should verify the efficiency of the coating over longer term period. In addition, repeated measures sampling would be needed to obtain more precise estimate of the decline in coating efficiency over time.

\section{Concluding Remarks}

The results of the present study clearly showed that the elastomer-based coating can be a very useful antifouling coating against zebra mussels for submerged fixed structures in confined freshwater environments such as docks 
and pontoons in marinas. Presumably, it could also be used inside reservoirs, pumping stations or even ships ballast tanks, with the caveat that the coating was found ineffective in marine waters. Our tests showed that leachates from the elastomer-based coating were safe with regards to drinking water guidelines and did not induce any toxic responses, making the coating absolutely innocuous for the environment. Notwithstanding the effectiveness of the coating on fixed structures in confined freshwater environments, the product should undergo future testing of its performance and resistance to abrasion when applied on mobile floating substrates such as boats and barges.

\section{Acknowledgements}

We wish to thank Michel DeBlois, from MD Technologies, for providing the ZebraOut ${ }^{\mathcal{O}}$ coating material, Denis Labonté for plates analysis and zebra mussels enumeration and size measurements, and François Boudreault for image analysis and sponge cover estimation. This study was funded by the aquatic invasive species research program at Centre Saint-Laurent, Environment Canada and by the St. Lawrence Action Plan.

\section{References}

Ackerman, J. D., Sim, B., Nichols, S. J., \& Claudi, R. (1994). A review of the early life history of zebra mussels (Dreissena polymorpha): Comparisons with marine bivalves. Canadian Journal of Zoology, 72, 1169-1179. http://dx.doi.org/10.1139/z94-157

Ackerman, J. D., Cottrell, C. M., Ethier, C. R., Allen, D. G., \& Spelt, J. K. (1996). Attachment strength of zebra mussels on natural, polymeric, and metallic materials. Journal of Environmental Engineering, 2, 141-148. http://dx.doi.org/10.1061/(ASCE)0733-9372(1996)122:2(141)

Aldridge, D. C., Elliott, P., \& Moggridge, G. D. (2006). Microencapsulated BioBullets for the control of biofouling zebra mussels. Environmental Science and Technology, 40, 975-979. http://dx.doi.org/10.1021/ es050614

Angarano, M. B., McMahon, R. F., Hawkins, D. L., \& Schetz, J. A. (2007). Exploration of structure-antifouling relationships of capsaicin-like compounds that inhibit zebra mussel (Dreissena polymorpha) macrofouling. Biofouling, 23, 295-305. http://dx.doi.org/10.1080/08927010701371439

Angarano, M. B., McMahon, R. F., \& Schetz, J. A. (2009). Cannabinoids inhibit zebra mussel (Dreissena polymorpha) byssal attachment: A potentially green antifouling technology. Biofouling, 25, 127-138. http://dx.doi.org/10.1080/08927010802592743

Bernabeu, A., Vicente, R., Peribanez, M. A., Arques, A., \& Amat, A. M. (2011). Exploring the applicability of solar driven photocatalytic processes to control infestation by zebra mussel. Chemical Engineering Journal, 171, 490-494. http://dx.doi.org/10.1016/j.cej.2011.04.009

Bowling, J. J., Mohammed, R., Diers, J. A., \& Hamann, M. T. (2010). Abundant ketone isolated from oily Plakortis sponge demonstrates antifouling properties. Chemoecology, 20, 207-213. http://dx.doi.org/10. 1007/s00049-010-0049-z

Brines Miller, E., \& Watzin, M. C. (2007). The effects of zebra mussels on the lower planktonic foodweb in Lake Champlain. Journal of Great Lakes Research, 33, 407-420. http://dx.doi.org/10.3394/0380-1330(200 7)33[4 07:TEOZMO]2.0.CO;2

Bueley, C., Olender, D., \& Bocking, B. (2014). In-situ trial of UV-C as an antifoulant to reduce biofouling induced measurement error. Journal of Ocean Technology, 9, 49-67. Retrieved from http://www.thejot.net/? page_id $=837 \&$ show_article_preview $=601$

Callow, J. A., \& Callow, M. E. (2011). Trends in the development of environmentally friendly fouling-resistant marine coatings. Nature Communications, 2, 244. http://dx.doi.org/10.1038/ncomms1251

Carrington, E. (2002). Seasonal variation in the attachment strength of blue mussels: Causes and consequences. Limnololy and Oceanography, 47, 1723-1733. http://dx.doi.org/10.4319/lo.2002.47.6.1723

Chambers, L. D., Stokes, K. R., Walsh, F. C., \& Wood, R. J. K. (2006). Modern approaches to marine antifouling coatings. Surface \& Coatings Technology, 201, 3642-3652. http://dx.doi.org/10.1016/j.surfcoat.2006.08.129

Claudi, R., \& Mackie, G. L. (1994). Practical manual for zebra mussel monitoring and control (pp. 1-251). Boca Raton (US), CRC Press.

Cope, W. G., Bartsch, M. R., \& Marking, L. L. (1997). Efficacy of candidate chemicals for preventing attachment of zebra mussels (Dreissena polymorpha). Environmental Toxicology and Chemistry, 16, 1930-1934. http://dx.doi.org/10.1002/etc.5620160923 
Costa, R., Elliott, P., Saraiva, P. M., Aldridge, D., \& Moggridge, G. D. (2008a). Development of sustainable solutions for zebra mussel control through chemical product engineering. Chinese Journal of Chemical Engineering, 16, 435-440. http://dx.doi.org/10.1016/S1004-9541(08)60101-9

Costa, R., Aldridge, D. C., \& Moggridge, G. D. (2008b). Seasonal variation of zebra mussel susceptibility to molluscicidal agents. Journal of Applied Ecology, 45, 1712-1721. http://dx.doi.org/10.1111/j.1365 $-2664.2008 .01555 . \mathrm{x}$

Costa, R., Aldridge, D. C., \& Moggridge, G. D. (2011a). Preparation and evaluation of biocide-loaded particles to control the biofouling zebra mussel, Dreissena polymorpha. Chemical Engineering Research and Design, 89, 2322-2329. http://dx.doi.org/10.1016/j.cherd.2011.02.027

Costa, R., Elliott, P., Aldridge, D. C., \& Moggridge, G. D. (2011b). Enhanced mortality of the biofouling zebra mussel, Dreissena polymorpha, through the application of combined control agents. Journal of Great Lakes Research, 37, 272-278. http://dx.doi.org/10.1016/j.jglr.2011.01.005

Costa, R., Aldridge, D. C., \& Moggridge, G. D. (2012). Multicomponent molluscicide mixtures for zebra mussel control. Journal of Great Lakes Research, 38, 317-325. http://dx.doi.org/10.1016/j.jglr.2012.03.010

Cusson, B., \& de Lafontaine, Y. (1997). Présence et abondance des larves de Moules zébrées dans la rivière Richelieu et le Saint-Laurent en 1996. Environnement Canada - Région du Québec, Conservation de l'environnement, Centre Saint-Laurent, Rapport Scientifique et Technique, ST-143, 58p.

Dafforn, K. A., Lewis, J. A., \& Johnston, E. L. (2011). Antifouling strategies: History and regulation, ecological impacts and mitigation. Marine Pollution Bulletin, 62, 453-465. http://dx.doi.org/10.1016/j.marpolbul. 2011.01.012

de Lafontaine, Y., Lapierre, L., Henry, M., \& Grégoire, Y. (1995). Abondance des larves de Moule zébrée (Dreissena polymorpha) et de Quagga (Dreissena bugensis) aux abords des centrales hydroélectriques de Beauharnois, Les Cèdres et Rivière-des-Prairies. Environnement Canada - Région du Québec, Conservation de l'environnement, Centre Saint-Laurent, Rapport Scientifique et Technique, ST-14, 52p.

de Lafontaine, Y., Costan, G., \& Delisle, F. (2002). Testing a new anti-zebra mussel coating with a multi-plate sampler: Confounding factors and other fuzzy features. Biofouling, 18, 1-12. http://dx.doi.org/10.1080/ 08927010290017671

de Lafontaine, Y., Despatie, S. P., \& Wiley, C. (2008). Effectiveness and potential toxicological impact of the PERACLEAN ${ }^{\circ}$ Ocean ballast water treatment technology. Ecotoxicology and Environmental Safety, 71, 355-369. http://dx.doi.org/10.1016/j.ecoenv.2007.10.033

de Lafontaine, Y., Chambers, Y., Despatie, S. P., Gagnon, C., \& Blaise, C. (2013). Effectiveness and potential environmental impact of a yeast-based deoxygenation process for treating ship ballast waters. Water Quality Research Journal of Canada, 48, 55-75. http://dx.doi.org/10.2166/wqrjc.2013.117

Diers, J. A., Pennaka, H. K., Peng, J., Bowling, J. J., Duke, S. O., \& Hamann, M. T. (2004). Structural activity relationship studies of zebra mussel antifouling and antimicrobial agents from verongid sponges. Journal of Natural Products, 67, 2117-2120. http://dx.doi.org/10.1021/np040097t

Diers, J. A., Bowling, J. J., Duke, S. O., Wahyuono, S., Kelly, M., \& Hamann, M. T. (2006). Zebra mussel antifouling activity of the marine natural product aaptamine and analogs. Marine Biotechnology, 8, 366-372. http://dx.doi.org/10.1007/s10126-005-6055-4

Early, T. A., \& Glonek, T. (1999). Zebra Mussel Destruction by a Lake Michigan Sponge: Populations, in Vivo ${ }^{31} \mathrm{P}$ Nuclear Magnetic Resonance, and Phospholipid Profiling. Environmental Science and Technology, 33, 1957-1962. http://dx.doi.org/10.1021/es980874

Farsad, N., \& Sone, E. D. (2012). Zebra mussel adhesion: Structure of the byssal adhesive apparatus in the freshwater mussel, Dreissena polymorpha. Journal of Structural Biology, 177, 613-620. http://dx.doi.org/10. 1016/j.jsb.2012.01.011

Folino-Rorem, N., Stoeckel, J., Thorn, E., \& Page, L. (2006). Effects of artificial filamentous substrate on zebra mussel (Dreissena polymorpha) settlement. Biological Invasions, 8, 89-96. http://dx.doi.org/10.1007/ s10530-005-0330-1

Gagné, F. (2006). Acute toxicity assessment of liquid samples with primary cultures of rainbow trout hepatocytes. In C. Blaise, \& J-F. Ferard (Eds.), Small-scale freshwater toxicity investigations. Vol. 1 Toxicity Test Methods (pp. 453-472). Netherlands, Springer. 
Greenberg, A. E., Clesceri, L. S., \& Eaton, A. D. (1992). Standard methods for the examination of water and wastewater $\left(18^{\text {th }}\right.$ Edition). Retrieved from http://www.mwa.co.th/download/file_upload/SMWW_10003000.pdf

Grutters, B. M., Verhofstad, M. J., van der Velde, G., Rajagopal, S., \& Leuven, R. S. (2012). A comparative study of byssogenesis on zebra and quagga mussels: the effects of water temperature, salinity and light-dark cycle. Biofouling, 28, 121-129. http://dx.doi.org/10.1080/08927014.2012.654779

Hellio, C., \& Yebra, D. M. (2009). Advances in marine antifouling coatings and technologies. Cambridge. Woodhead Publishing Ltd.

Howell, D., \& Behrends, B. (2010). Consequences of antifouling coatings - The chemist's perspective. In S. Dürr \& J. C. Thomason (Eds.), Biofouling (pp. 226-242). Oxford (UK): Wiley-Blackwell.

Karatayev, A., Burlakova, L., \& Padilla, D. (2002). Impacts of zebra mussels on aquatic communities and their role as ecosystem engineers. In E. Leppäkoski, S. Gollasch, \& S. Olenin (Eds.), Invasive Aquatic Species of Europe. Distribution, Impacts and Management (pp. 433-446). Netherlands: Springer.

Kavouras, J. H., \& Maki, J. S. (2003a). The effects of natural biofilms on the reattachment of young adult zebra mussels to artificial substrates. Biofouling, 19, 247-256. http://dx.doi.org/10.1080/0892701032000077149

Kavouras, J. H., \& Maki, J. S. (2003b). Effects of biofilm on zebra mussel postveliger attachment to artificial surfaces. Invertebrate Biology, 122, 138-151. http://dx.doi.org/10.1111/j.1744-7410.2003.tb00079.x

Kilgour, B. W., Mackie, G. L., Baker, M. A., \& Keppel, R. (1994). Effects of salinity on the condition and survival of Zebra mussels (Dreissena polymorpha). Estuaries, 17, 385-393. http://dx.doi.org/10.2307/ 1352671

Kobak, J. (2001). Light, gravity and conspecifics as cues to site selection and attachment behaviour of juvenile and adult Dreissena polymorpha Pallas, 1771. Journal of Molluscan Studies, 67, 183-189. http://dx.doi.org/ 10.1093/mollus/67.2.183

Kobak, J. (2005). Recruitment and distribution of Dreissena polymorpha (Bivalvia) on substrates of different shape and orientation. International Review of Hydrobiology, 90, 159-170. http://dx.doi.org/10.1002/ iroh.200410756

Kobak, J. (2006). Factors affecting the attachment strength of Dreissena polymorpha (Bivalvia). Biofouling, 22, 141-150. http://dx.doi.org/10.1080/08927010600691895

Kobak, J., \& Nowacki, P. (2007). Light-related behaviour of the zebra mussel (Dreissena polymorpha, Bivalvia). Fundamental and Applied Limnology Archiv fur Hydrobiologie, 169, 341-352. http://dx.doi.org/10.1127/ 1863-9135/2007/0169-0341

Kobak, J., \& Kakareko, T. (2009). Attachment strength, aggregation and movement of the zebra mussel (Dreissena polymorpha, Bivalvia) in the presence of potential predators. Fundamental and Applied Limnology Archiv fur Hydrobiologie, 174, 193-204. http://dx.doi.org/10.1127/1863-9135/2009/0174-0193

Kobak, J., Poznanska, M., \& Kakareko, T. (2009). Effect of attachment status and aggregation on the behaviour of the zebra mussel Dreissena polymorpha. Journal of Molluscan Studies, 75, 119-126. http://dx.doi.org/10. 1093/mollus/eyn046

Lancioni, T., \& Gaino, E. (2005). Competition between the freshwater sponge Ephydatia fluviatilis and the zebra mussel Dreissena polymorpha in Lake Trasimeno (central Italy). Italian Journal of Zoology, 72, 27-32. http://dx.doi.org/10.1080/11250000509356649

Lauer, T. E., \& Spacie, A. (2004). Space as a limiting resource in freshwater systems: Competition between zebra mussels (Dreissena polymorpha) and freshwater sponges (Porifera). Hydrobiologia, 517, 137-145. http://dx.doi.org/10.1023/B:HYDR.0000027342.31716.9a

Lewis, J. A. (2009). Non-silicone biocide-free antifouling solutions. In C. Hellio, \& D. M. Yebra (Eds.), Advances in marine antifouling coatings and technologies (pp. 709-724). Cambridge, Woodhead Publishing Ltd.

Maréchal, J-P., \& Hellio, C. (2009). Challenges for the development of new non-toxic antifouling solutions. International Journal of Molecular Sciences, 10, 4623-4637. http://dx.doi.org/10.3390/ijms10114623

Marsden, J. E., \& Lansky, D. M. (2000). Substrate selection by settling zebra mussels, Dreissena polymorpha, relative to material, texture, orientation, and sunlight. Canadian Journal of Zoology, 78, 787-793. http://dx.doi.org/10.1139/z00-004 
Martin, M. D., Mackie, G. L., \& Baker, M. A. (1993). Control of the Biofouling Mollusc, Dreissena polymorpha (Bivalvia: Dreissenidae), with sodium hypochlorite and with polyquaternary ammonia and benzothiazole compounds. Archives of Environmental Contamination and Toxicology, 24, 381-388. http://dx.doi.org/ $10.1007 / \mathrm{BF} 01128738$

MD Technologies. (2008). ZebraOut. Retrieved from http://mdtech1996.blogspot.com/2008/02/zbraout.html

Molloy, D. P., Karatayev, A. Y., Burlakova, L. E., Kurandina, D. P., \& Laruelle, F. (1997). Natural enemies of zebra mussels: Predators, parasites, and ecological competitors. Reviews in Fisheries Science, 5, 27-97. http://dx.doi.org/10.1080/10641269709388593

Molloy, D. P., Mayer, D. A., Gaylo, M. J., Morse, J. T., Presti, K. T., Sawyko, P. M., ... Griffin, B. H. (2013). Pseudomonas fluorescens strain CL145A - a biopesticide for the control of zebra and quagga mussels (Bivalvia: Dreissenidae). Journal of Invertebrate Pathology, 113, 104-114. http://dx.doi.org/10.1016/j.jip. 2012.12.012

Morse, J. T. (2009). Assessing the effects of application time and temperature on the efficacy of hot-water sprays to mitigate fouling by Dreissena polymorpha (Pallas). Biofouling, 25, 605-610. http://dx.doi.org/10.1080/ 08927010902989245

Pimentel, D., Zuniga, R., \& Morrison, D. (2005). Update on the environmental and economic costs associated with alien-invasive species in the United States. Ecological Economics, 52, 273-288. http://dx.doi.org/10. 1016/j.ecolecon.2004.10.002

Qian, P-Y., Xu, Y., \& Futesani, N. (2010). Natural products as antifouling compounds: recent progress and future perspectives. Biofouling, 26, 223-234. http://dx.doi.org/10.1080/08927010903470815

Ram, J. L., Fong, P. P., \& Garton, D. W. (1996). Physiological aspects of zebra mussel reproduction: maturation, spawning, and fertilization. American Zoologist, 36, 326-338. Retrieved from http://www.jstor.org/stable/ 3884094

Regoli, L., Chan, H. M., de Lafontaine, Y., \& Mikaelian, I. (2001). Organotins in zebra mussels (Dreissena polymorpha) and sediments of the Quebec City Harbour area of the St. Lawrence River. Aquatic Toxicology, 53, 115-126. http://dx.doi.org/10.1016/S0166-445X(00)00174-0

Sanchez, A., \& Yebra, D. M. (2009). Ageing tests and long-term performance of marine antifouling coatings. In C. Hellio, \& D. M. Yebra (Eds.), Advances in marine antifouling coatings and technologies (pp. 393-421). Cambridge, Woodhead Publishing Ltd.

Swain, G., Herpe, S., Ralston, E., \& Tribou, M. (2006). Short-term testing of antifouling surfaces: the importance of colour. Biofouling, 22, 425-429. http://dx.doi.org/10.1080/08927010601037163

Townsin, R. L., \& Anderson, C. D. (2009). Fouling control coatings using low surface energy, foul release technology. In C. Hellio, \& D. M. Yebra (Eds.), Advances in marine antifouling coatings and technologies (pp. 693-708). Cambridge, Woodhead Publishing Ltd.

Van Appledorn, M., \& Bach, C. E. (2007). Effects of zebra mussels (Dreissena polymorpha) on mobility of three native mollusk species. American Midland Naturalist, 158, 329-337.

Webster, D. C., \& Chisholm, B. J. (2010). New directions in antifouling technologies. In S. Durr, \& J. C. Thomason (Eds.), Biofouling (pp. 366-387). New-York, Wiley-Blackwell.

Wells, A. W., Meyer, A. E., Matousek, J. A., Baier, R. E., \& Neuhauser, E. F. (1997). Nontoxic foul-release coatings for zebra mussel control (pp. 451-460). Waterpower'97, Proceedings of the International Conference on Hydropower, American Society of Civil Engineers, Atlanta (US).

\section{Copyrights}

Copyright for this article is retained by the author(s), with first publication rights granted to the journal.

This is an open-access article distributed under the terms and conditions of the Creative Commons Attribution license (http://creativecommons.org/licenses/by/4.0/). 